\title{
Pusat Kuliner Dengan Pendekatan Arsitektur Metafora Di SURAKARTA
}

\author{
Ristiara Wantemas, Ofita Purwani, Sri Yuliani \\ Program Studi Arsitektur \\ Universitas Sebelas Maret Surakarta \\ Email : ririshakimmm@gmail.com
}

\begin{abstract}
:
The potential of Indonesian culinary field is increasing every year, indicated by inflation in the business sector and culinary tourism. This suggests a potential in the culinary field to be developed. The strategy to support the national culinary development program includes improving the quality of education in the culinary field. Therefore it takes an educational space that is able to develop creative human resources in the culinary field. Culinary field is one of the promising areas in the development of Surakarta travel, so other than as an educational space, a culinary center can be a tourist attraction culinary Surakarta. Metaphor Architecture is used as an approach in the planning and architecture, considering that Metaphor Architecture can visually communicate the building functions to the public. Architectural Metaphor used is Tangible Architectural Metaphor, so that the form will be designed in such Metaphor to be able to communicate the existence of Culinary Center and Culinary landmark of Surakarta City. Problems in planning and designing Culinary Center ie what form it will be used as the basis of an analogy to be a metaphor? Be used stages of creative thinking in design the Culinary Center with Metaphor Architectural Approach. Based on typical food survey Solo, liwet rice has the highest number of respondents as the most representative food the city of Solo , so liwet rice will be to the main idea into a form that will be used as a metaphor in designing Culinary Center
\end{abstract}

Keywords: Culinary Education, Culinary Center, Creative Thinking, Metaphor Architecture, Tangible Metaphor Architecture

\section{PENDAHULUAN}

Potensi kuliner Indonesia meningkat setiap tahunnya, ditandai dengan adanya inflasi pada sektor usaha dan pariwisata kuliner (Badan Pusat Statistik 2015). Selain itu pertumbuhan bisnis makanan dan minuman olahan mendongkrak pemasukan ekspor Indonesia (Perkembangan Ekspor Indonesia Berdasarkan Sektor 2015). Hal ini menunjukkan adanya potensi dalam bidang kuliner untuk dikembangkan, berkaitan dengan program pengembangan kuliner nasional 2015-2019 (program.indonesiakreatif.net 2015).

Beberapa strategi dalam mendukung program pengembangan kuliner nasional antara lain meningkatkan kualitas pendidikan bidang kuliner, memfasilitasi pemberdayaan dan pelatihan juru masak untuk meningkatkan kemampuan mengolah kuliner dengan standar global, mengenalkan konsep kewirausahaan kepada masyarakat secara berkualitas, berkelanjutan dan lain-lain (program.indonesiakreatif.net 2015). Untuk itu dibutuhkan suatu ruang edukasi yang mampu mengembangkan sumber daya manusia yang kreatif dalam bidang kuliner. Sarana edukatif di bidang kuliner seperti kursus, seminar dan sekolah formal/non-formal dapat menjadi alternatif masyarakat untuk memperkaya pengetahuan kuliner (program.indonesiakreatif.net 2015)

Kuliner adalah salah satu bidang yang diunggulkan oleh pemerintah Kota Surakarta untuk mempromosikan pariwisata. Seiring dengan perkembangan wisata Kota Surakarta, bidang kuliner adalah salah satu bidang yang menjanjikan dalam pengembangan wisata Kota Surakarta (Solo Culinary Destination | Portal Informasi Kota Surakarta 2015). Hal ini berkaitan dengan adanya peningkatan usaha restoran, hotel, dan pariwisata yang ada di Kota Surakarta (Badan Pusat Statistik Kota Surakarta 2015). 
Pusat Kuliner merupakan ruang edukasi kuliner yang diharapkan dapat memfasilitasi kegiatan pengembangan kuliner lokal yang di dalamnya terdapat kelas edukasi non-formal seperti kursus, seminar, lokakarya dan penelitian.

Selain sebagai ruang edukasi, Pusat Kuliner dapat menjadi daya tarik wisata kuliner Kota Surakarta dengan kegiatan pameran kuliner. Untuk mendukung fungsi pariwisata dibutuhkan unsur-unsur bangunan yang dapat menarik pengunjung untuk datang dan berkegiatan di dalamnya, salah satunya adalah bentuk yang menarik. Oleh karena itu dibutuhkan bentuk yang menarik yang dapat merepresentasikan fungsi bangunan (Fatimath 2015). Selain bentuk yang menarik, bentuk bangunan juga diharapkan mampu untuk mengkomunikasikan keberadaan Pusat Kuliner di Surakarta. Untuk itu diambil Arsitektur Metafora sebagai pendekatan dalam proses perencanaan dan perancangan Pusat Kuliner dengan pertimbangan bahwa Arsitektur Metafora dapat menyampaikan misi dari fungsi bangunan yang dikomunikasikan secara visual kepada publik. Bentuk yang akan dimetaforakan harus dapat mengkomunikasikan keberadaan Pusat Kuliner dan tengara (landmark) Surakarta sebagai Kota Kuliner

Permasalahan dalam penyusunan perencanaan dan perancangan Pusat Kuliner dengan Pendekatan Arsitektur Metafora di Surakarta antara lain kegiatan apa saja yang akan diwadahi dalam Pusat Kuliner? Bentuk apa yang akan diambil sebagai analogi dasar untuk dimetaforakan sehingga dapat merepresentasikan Pusat Kuliner sebagai ruang edukasi kuliner yang bersifat non-formal di Kota Surakarta? Bagaimana mengembangkan bentuk dasar menjadi desain akhir Pusat Kuliner di Surakarta dengan pendekatan Arsitektur Metafora?

Tujuan dari studi ilmiah ini yaitu dapat merancang Pusat Kuliner di Kota Surakarta dengan pendekatan Arsitektur Metafora

\section{METODE}

Arsitektur Metafora merupakan bagian dari analogi desain (Broadbent, Bunt, and Jencks 1980). Dalam analogi desain terdapat beberapa cara untuk merancang suatu desain, salah satunya dengan cara creative thinking
(Mahmoodi 2015). Pada creative thinking terdapat tiga tahapan dalam proses desain.

A. Synthesizing

Yaitu proses menentukan bentuk yang akan dimetaforakan dan jenis desain Arsitektur Metafora yang digunakan. Dalam proses ini dilakukan survey terhadap makanan khas Kota Solo yang menurut publik paling representatif terhadap Kota Solo

Hasil dari survey menunjukkan dari beberapa makanan khas yang ada di Solo, nasi liwet merupakan makanan yang paling representatif terhadap Kota Solo dengan prosentase sebesar $47.5 \%$. Nasi liwet menjadi bagian dari ide awal bentuk yang akan dimetaforakan

Bentuk Metafora yang digunakan adalah Metafora Konkret, yaitu Metafora yang ditunjukkan secara fisik pada desain, sehingga dengan jelas akan terlihat oleh publik.

\section{B. Elaborating}

Proses pengolahan ide awal desain dengan memasukkan aspek analisis kegiatan, kebutuhan ruang yang didapatkan dari preseden, tapak, struktur.

C. Imagining

Proses refleksi, evaluasi terhadap ide desain untuk melihat apakah ide desain tersebut sudah cukup merepresentasikan misi dari Pusat Kuliner.

\section{ANALISIS}

\subsection{Analisis Peruangan}

Pada tahap elaborating telah dilakukan studi preseden kegiatan pada objek Pusat Kuliner. Preseden tersebut antara lain Basque Culinary Center, International Culinary Center dan Jakarta Culinary Center. Dari ketiga preseden di atas ditemukan beberapa kegiatan dalam Pusat Kuliner. Beberapa kegiatan utamanya antara lain pelatihan mengolah makanan, penelitian gizi dan makanan dan inovasi pengembangan kuliner. Kemudian kegiatan tambahan yang ada di Pusat Kuliner antara lain pelatihan pengembangan manajemen, usaha kuliner dan pameran karya kuliner.

\subsection{Analisis Lokasi}

Berdasarkan kriteria Pusat Kuliner secara umum maka dipilih tapak yang berada 
di Kelurahan Karangasem, Kecamatan Laweyan, tepatnya di sebelah utara Jalan Adi Sucipto, berdekatan dengan Kantor DPRD Kota Surakarta.

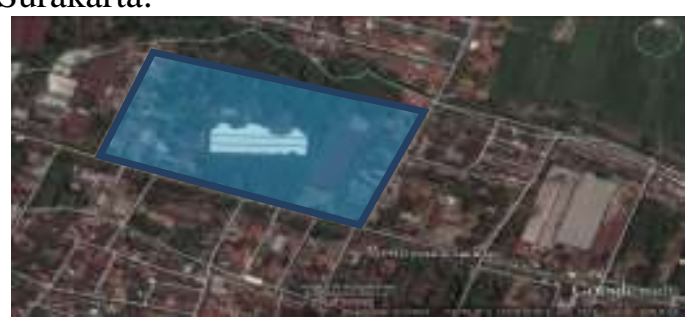

Gambar 1 Lokasi Tapak Pusat Kuliner Sumber : www.googlemaps.com

Alasan pemilihan lokasi tapak antara lain: sesuai dengan RTRW Kota Surakarta yaitu berada di kawasan yang digunakan untuk pendidikan dan pariwisata, akses yang mudah dicapai, berada pada jalur masuk wisata Kota Surakarta (akses Bandara Adi Sumarmo menuju Kota Surakarta), dekat dengan kota, fasilitas pendukung infrastruktur yang telah tersedia, dapat langsung terlihat keberadaan Pusat Kuliner dari jalan utama Adi Sucipto.

\subsection{Analisis Pencapaian}

Akses utama untuk mencapai tapak yaitu Jalan Adi Sucipto yang merupakan jalan primer terdiri dari 2 lajur kendaraan, dari arah barat yaitu wilayah Colomadu, Bandara Adi Sumarmo dan dari arah timur wilayah Manahan atau Kota Solo.

\subsection{Analisis Hubungan Ruang}

Dalam perencanaan dan perancangan Pusat Kuliner di Surakarta kegiatan yang akan diwadahi yaitu pelatihan edukasi kuliner yang terdiri dari mengolah makanan dan inovasi pengembangan kuliner, penelitian gizi dan makanan serta kegiatan pameran karya kuliner sebagai kegiatan wisata kuliner di Surakarta.

Dari kegiatan tersebut maka menghasilkan program ruang sebagai berikut

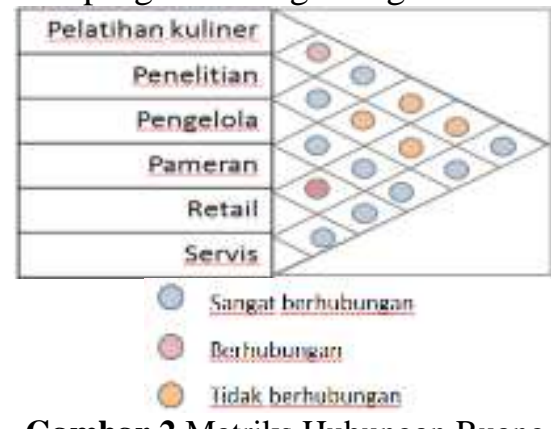

Gambar 2 Matriks Hubungan Ruang Pusat Kuliner

\subsection{Analisis Bentuk dan Tampilan Bangunan}

Dalam menentukan langkah desain Arsitektur Metafora Konkret, sebelumnya dilakukan studi preseden Arsitektur Metafora Konkret. Preseden tersebut antara lain Bank of Southrern Sudan, Lotus Temple dan Perputakaan Riau. Kesimpulan dari studi preseden Arsitektur Metafora Konkret yaitu ketiga bangunan tersebut mengolah bentuk metafora dengan mengambil unsur-unsur yang dapat mewakili fungsi dan tujuan bangunan. Unsur tersebut diolah bentuk dasarnya sehingga mendapatkan bentuk yang referesentatif terhadap bangunan yang direncanakan.

Maka dari itu Pusat Kuliner akan dirancang dengan menggabungkan beberapa unsur representatif dari nasi liwet, antara lain: pincuk daun pisang dengan unsur yang akan digunakan yaitu bentuk, warna, unsur lipat dan teksturnya, nasi liwet yang digunakan warna putihnya, sayur labu siam yang digunakan bentuk potongan dan warnanya, dan tekstur ceting bambu yang merupakan wadah nasi liwet saat matang.

1. Penggabungan Ide Dasar

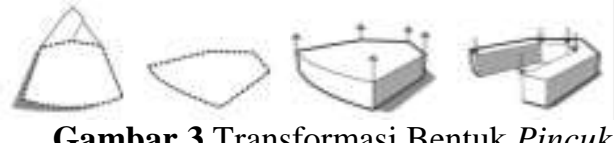

Gambar 3 Transformasi Bentuk Pincuk

Bentuk pincuk daun pisang jika dilihat dari sisi atas maka terlihat bentuk bidang dengan sudut yang melebar. Bentuk bidang ini menjadi bagian dari bentuk massa, yang kemudian diberikan pengurangan area di bagian tengahnya. Massa ini nantinya akan digunakan sebagai area publik yaitu untuk kegiatan pameran karya kuliner dan retail

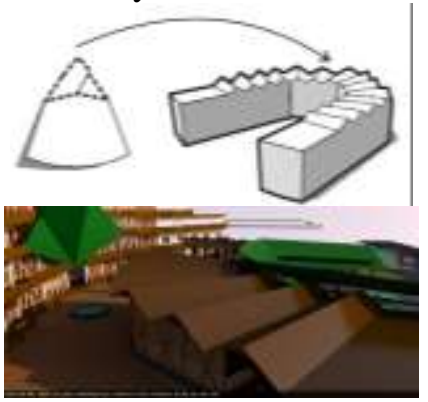


Gambar 4 Tranformasi Unsur Lipat Pada Pincuk

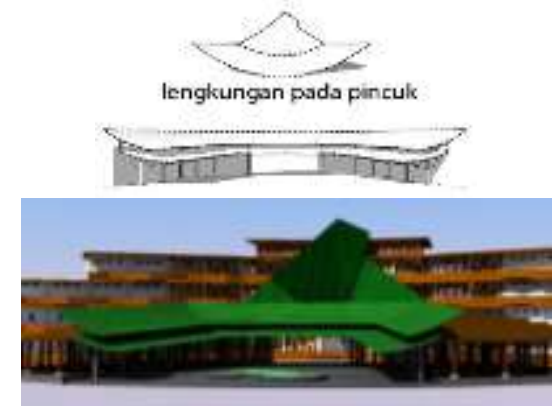

Gambar 5 Penggunaan Unsur Lengkung Pada Pincuk

Pincuk daun pisang mempunyai bagian yang terlipat, unsur lipatan digunakan pada bagian atap massa yang pertama. Sisi lengkung pincuk diaplikasikan pada bagian tengah massa pameran sebagai penguat identitas pincuk daun pisang.

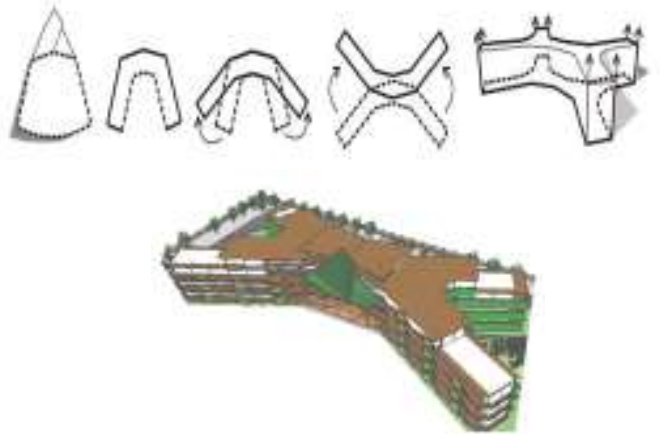

Gambar 6 Transformasi Bentuk Pincuk Sebagai Bentuk Massa Bangunan

Bidang dengan sudut melebar digunakan lagi untuk membentuk Massa kedua yaitu untuk fungsi kegiatan pelatihan dan penelitian. Dengan sudut yang lebih dilebarkan sehingga menghasilkan bentuk dasar massa yang memanjang horizontal. Bentuk tersebut dicerminkan dan divertikalkan sehingga membentuk massa yang masif. Bentuk dasar dicerminkan sehingga menghasilkan ruang di tengah pada setiap sisi kanan dan kirinya, hal ini berkaitan dengan mengoptimalkan sirkulasi udara alami untuk dapat masuk ke dalam bangunan.
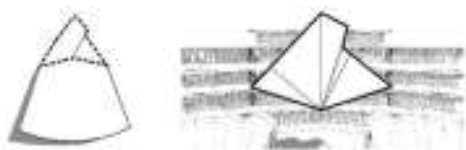

Gambar 7 Bentuk Modifikasi Lipatan Pincuk

Untuk terlihat lebih representatif bentuk lipatan pincuk diletakkan pada bagian massa kedua yaitu massa studi dan penelitian. Selain itu bagian ini juga menjadi pendukung point of interest pada bangunan yang menghasilkan kesan menyambungkan antara massa pameran dan massa studi.
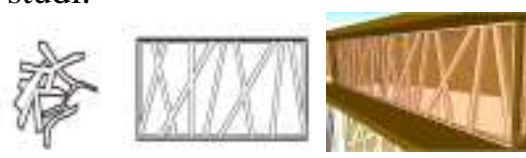

Gambar 8 Transformasi Bentuk Potongan Labu siam

Sayur labu siam pada nasi liwet mempuyai bentuk potongan kecil memanjang. Bentuk ini digunakan pada bagian dinding massa studi dan diberi warna jingga agar representatif terhadap publik.

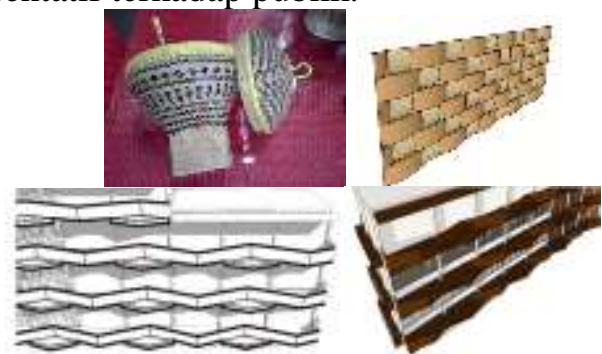

Gambar 9 Transformasi bentuk anyaman bambu

Bentuk anyaman bambu diaplikasikan pada bagian reling selasar. Dibentuk saling silang dengan plat lantai yang juga bagian dari plafon pada lantai di bawahnya sehingga dari sisi depan bangunan terlihat seperti anyaman.

2. Pola massa bangunan

Pola massa bangunan Pusat Kuliner menggunakan pola cluster, sebagai bentuk penyesuaian terhadap pola hubungan ruang yang ada di dalam Pusat Kuliner.

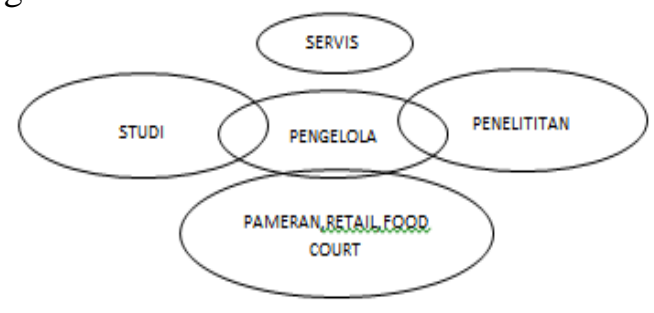




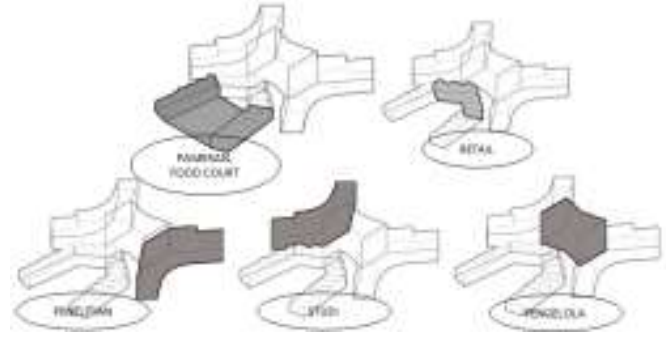

Gambar 10 Pola Massa Bangunan

Area kegiatan pameran dan retail diletakkan di bagian depan dimaksudkan merupakan area panggung/stage sedangkan area pelatihan dan penelitian diletakkan di bagian belakang atau backstage. Dalam hal ini peletakan area menggunakan filosofi dapur atau tempat memasak yang dalam istilah jawa disebut pawon berada dibelakang, sehingga area pelatihan atau tempat melakukan praktek memasak diletakkan di belakang. Sebagai identitas keberadaan Pusat Kuliner yang ada di Solo maka dimasukkan unsur suasana Solo pada bagian area pameran dan retail

\section{KESIMPULAN (KONSEP DESAIN)}

Pusat Kuliner adalah wadah untuk memfasilitasi kegiatan pendidikan kuliner yang bersifat non-formal sebagai sarana mengembangkan dan mendalami ilmu kuliner.

Pusat Kuliner terletak di Kelurahan Karangasem, Kecamatan Laweyan, Surakarta, tepatnya pada Jalan Adi Sucipto sebelah barat laut Kantor DPRD Kota Surakarta.

Pusat Kuliner dirancang dengan pendekatan Arsitektur Metafora. Bentuk dasar metafora Pusat Kuliner menggunakan unsurunsur makanan nasi liwet yang merupakan makanan khas Solo. Unsur-unsur tersebut antara lain: pincuk daun pisang, sambel goreng labu siam, dan ceting bambu.

Kegiatan yang ada di Pusat Kuliner terdiri dari kegiatan utama yaitu pelatihan ahli chef dan bisnis kuliner dan penelitian kuliner serta kegiatan penunjang yaitu pameran karya kuliner dan food court.

Dalam menerapkan konsep Arsitektur Metafora pada tahap perencanaan dan perancangan digunakan proses creative thinking dengan tahapan proses antara lain: synthesizing (proses eksplorasi ide dasar), elaborating (proses perencanaan yang menggabungkan ide dasar dengan aspek-aspek perancangan arsitektur dan imagining (proses refleksi hasil perencanaan).

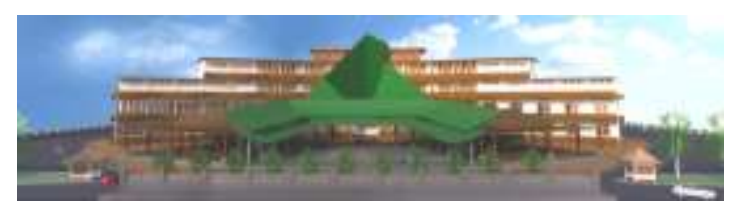

Gambar 11 Perspektif Tampak Depan Pusat Kuliner

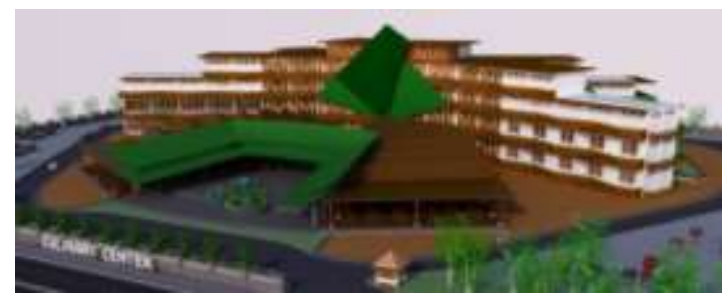

Gambar 12 Perspektif Mata Burung Pusat Kuliner

\section{REFERENSI}

Badan Pusat Statistik 2015. Accessed November 16.

http://www.bps.go.id/linkTableDinami s/view/id/896.

Badan Pusat Statistik Kota Surakarta 2015.

Accessed November 16.

http://surakartakota.bps.go.id/index.ph

p.

Broadbent, Geoffrey, Richard Bunt, and Charles Jencks. 1980. Signs, Symbols, and Architecture. Wiley.

Fatimath, Amira. 2015. "The Role of Stakeholder Collaboration in Sustainable Tourism Competitiveness : The Case of Auckland, New Zealand." University of Technology.

Mahmoodi, Amir. 2015. "The Design Process In Architecture A Pedagogic Approach Using Interactive Thinking." University o Leeds. Accessed November 6.

Perkembangan Ekspor Indonesia Berdasarkan Sektor 2015. Accessed November 16. http://www.kemenperin.go.id/statistik/ peran.php?ekspor $=1$.

program.indonesiakreatif.net, 2015. 2015. "Rencana Pengembangan Kuliner Indonesia." In Program Indonesia Kreatif. 
Solo Culinary Destination | Portal Informasi Kota Surakarta 2015. Accessed

November 4.

http://www.surakarta.go.id/konten/sol

o-culinary-destination. 